\title{
La producción de semillas en la provincia de Bolívar y la importancia del suelo
}

\author{
Seed production in the province of Bolívar and the importance of the soil
}

Produção de sementes na província de Bolívar e a importância do solo

Rubén Saltos
rudasaes@yahoo.es
Edwin Lara
laraed702@gmail.com

Ministerio de Agricultura Ganadería Acuacultura y Pesca- MAGAP. Dirección Agropecuaria de Bolívar, Ecuador

Artículo recibido septiembre 2018, arbitrado octubre 2018 y publicado en enero 2019

\section{RESUMEN}

La iniciativa del presente artículo es mostrar el fomento en la producción para el acceso y uso de semilla de calidad para pequeños y medianos productores de la provincia de Bolívar en Ecuador. La metodología empleada se basa en la identificación de potenciales organizaciones de pequeños y medianos agricultores legalmente constituidas con enfoque empresarial; con las cuales se crearon parcelas demostrativas fomentando el uso de semilla de calidad. El proyecto está ubicado en la provincia de Bolívar en los cantones como Guaranda, Chimbo, San Miguel y Chillanes. Para finalizar se tiene que la producción de semillas desde el punto de vista empresarial de las organizaciones está encaminado hacia el cambio de la matriz productiva; cuya sostenibilidad depende de varios factores como la planificación, organización, valores corporativos. Además de la modificación en las normativas de producción de semilla en Ecuador permite que se cumplan con los parámetros exigidos por la ley para garantizar la semilla de calidad. En la provincia de Bolívar existe una demanda insatisfecha sobre el acceso a semillas de calidad que debe ser cubierta.

Palabras clave: semillas; producción; sostenibilidad

\begin{abstract}
The initiative of this article is to show the promotion in the production for the access and use of quality seed for small and medium producers in the province of Bolívar in Ecuador. The methodology used is based on the identification of potential organizations of small and medium farmers legally constituted with a business focus; with which demonstration plots were created promoting the use of quality seed. The project is located in the Bolívar province in the cantons such as Guaranda, Chimbo, San Miguel and Chillanes. Finally, seed production from the business point of view of the organizations is aimed at changing the productive matrix; whose sustainability depends on various factors such as planning, organization, corporate values. In addition to the modification in the regulations for seed production in Ecuador, it allows the parameters required by law to be complied with to guarantee quality seed. In the province of Bolívar there is an unmet demand for access to quality seeds that must be covered.
\end{abstract}

Key words: seeds; production; sustainability 


\section{RESUMO}

A iniciativa deste artigo é mostrar a promoção da produção para o acesso e uso de sementes de qualidade para pequenos e médios produtores na província de Bolívar, no Equador. A metodologia utilizada é baseada na identificação de organizações potenciais de pequenos e médios agricultores legalmente constituídos com foco nos negócios; com o qual foram criadas parcelas de demonstração promovendo o uso de sementes de qualidade. 0 projeto está localizado na província de Bolívar, nos cantões como Guaranda, Chimbo, San Miguel e Chillanes. Finalmente, a produção de sementes do ponto de vista comercial das organizações visa mudar a matriz produtiva; cuja sustentabilidade depende de vários fatores, como planejamento, organização e valores corporativos. Além da modificação dos regulamentos para produção de sementes no Equador, permite que os parâmetros exigidos por lei sejam cumpridos para garantir a qualidade das sementes. Na província de Bolívar, existe uma demanda não atendida por acesso a sementes de qualidade que devem ser cobertas.

Palavras-chave: $\quad$ sementes; $\quad$ produção; sustentabilidade

\section{INTRODUCCIÓN}

Dentro de los sistemas de producción de los agricultores de la provincia de Bolívar es muy común la utilización de "grano" como semilla de la cosecha anterior que no es la de mejor calidad; esta actividad resulta insuficiente para garantizar la producción y productividad de los cultivos.

El uso de semilla certificada de papa, representó a nivel nacional sólo el 2,73\% de la superficie sembrada, en la región sierra representó el $2,75 \%$ de la superficie sembrada, en la provincia de Chimborazo el 0,02\% y en la de Bolívar el 0,14\%. Del mismo modo la Superficie de fréjol sembrada con semilla certificada a nivel nacional fue de tan sólo de 347 hectáreas de las cuales en la región sierra ocupaban 97 hectáreas, para el caso de la provincias de Chimborazo y Bolívar no existe ningún registro, similar situación ocurre con la superficie de maíz amiláceo sembrada y el uso de semilla certificada (ESPAC - INEC, 2011; citado por Pulgar, 2012).

Sin embargo; la producción y provisión de semillas de calidad históricamente ha tenido un comportamiento más bien irregular, como producto de una combinación de FACTORES AMBIENTALES, políticos y de mercado que ha configurado una situación de desventaja casi permanente especialmente para los pequeños productores (Pulgar, 2012).

Las actividades humanas han aumentado en cuanto a intensidad, afectando la diversidad biológica de los ecosistemas y vulnerando en muchos casos esta capacidad de respuesta con resultados negativos (Saltos y Saltos, 2011). Los microorganismos patógenos en el suelo que atacan en este caso alcultivo de papa en Ecuador están: costra negra (Rhizoctonia solani), roña (Spongospora subterranea), pudrición seca (Fusariun spp), sarna (Streptomyces scabies), pie negro (Pectobacterium $\mathrm{sp}$ ). Estas enfermedades a más de causar pérdidas, deterioran la calidad del producto y contaminan los suelos de los cultivos (Mora, et al. 2011). 
Tabla 1. Impacto del complejo de microorganismos del tubérculo semilla y su relación al desarrollo del cultivo de papa.

\begin{tabular}{|c|c|c|c|c|}
\hline \multirow{2}{*}{ ENFERMEDAD } & \multirow{2}{*}{$\begin{array}{c}\text { DURANTE EL } \\
\text { CULTIVO } \\
\begin{array}{c}\text { Emergencia } \\
\text { regulas }\end{array} \\
\end{array}$} & \multicolumn{2}{|c|}{ A LA COSECHA } & \multirow{2}{*}{$\begin{array}{c}\text { DURANTE EL } \\
\text { ALMACENAJE } \\
\begin{array}{c}\text { Pérdida de } \\
\text { calidad }\end{array} \\
\end{array}$} \\
\hline & & $\begin{array}{c}\text { Rendimiento } \\
\text { total }\end{array}$ & $\begin{array}{l}\text { Calidad de } \\
\text { la cosecha }\end{array}$ & \\
\hline Costra negra (Rhizoctonia solani) & $* * * *$ & $* * *$ & $* * *$ & $*$ \\
\hline Sarna (Streptomyces scabies) & $\mathbf{0}$ & $*$ & $* * *$ & $* * *$ \\
\hline Pudrición seca (Fusariun spp) & $* * *$ & $*$ & $*$ & $* * * *$ \\
\hline Pie negro (Pectobacterium sp). & $* * *$ & $* * * *$ & $* * *$ & $* * * *$ \\
\hline
\end{tabular}

Adaptado por SCHNETTLER (2000); Saltos, R. 2018.

$\left(^{*}\right)$ Bajo potencial de impacto (**) Mediano potencial de impacto (***) Alto potencial de impacto (****) Muy alto potencial de impacto

Las enfermedades causadas por hongos son muy importantes en la producción de tubérculos-semillas de papa, (Tabla 1). Algunas pueden destruir las plantaciones, mientras que otras ocasionan pérdidas en los rendimientos y le restan calidad a los tubérculos. Por lo tanto los agricultores dedicados a la producción de tubérculossemillas deben tener los conocimientos y la experiencia necesaria para proteger sus cultivos y de esta forma tener campos de papa qué, además de dar buenos rendimientos, posean la sanidad que exige el reglamento de semillas de cada país (Torres. H. 2014).

El Acuerdo Ministerial 494 del 26 de octubre del 2012.Ley de semillas de Ecuador, en su Art. 41.- indica: que los campos objeto de la certificación deberán ser calificados respecto de la presencia de nemátodos, plagas y patógenos del suelo, clara delimitación y facilidad de acceso, con anterioridad suficiente a su fecha de siembra.

El propósito de este estudio es fomentar la producción para el acceso y uso de semilla de calidad para pequeños y medianos productores de la provincia de Bolívar.

\section{METODOLOGÍA}

El proyecto estuvo ubicado en la provincia de Bolívar en los cantones como Guaranda, Chimbo, San Miguel y Chillanes. Se identificaron potenciales organizaciones de pequeños y medianos agricultores legalmente constituidas con enfoque empresarial; con las cuales se crearon parcelas demostrativas fomentando el uso de semilla de calidad. Así mismo se identificó campos (lotes) que cumplan con las normativas vigentes como son: rotación de cultivos, aislamiento, entre otros, para la producción de semilla (Sistema formal). Se formó Escuelas de Campo para Agricultores (ECA`s), que es una metodología de capacitación participativa, basada en el concepto de aprender por descubrimiento, aprender- haciendo, en el que participantes y facilitadores intercambian conocimientos, donde se abordaron varias temáticas como: producción de semilla, fortalecimiento organizacional, manejo de suelos, MIPE. etc.

Se adquirió semilla categoría registradas y certificadas de las variedades: PAPA SUPERCHOLA, FREJOL- INIAP 481 ROJO DEL VALLE, MAÍZ INIAP 111, TRIGO INIAP 
MIRADOR, INIAP SAN JACINTO, provenientes del INIAP, con el cual se inició los planes de producción con las organizaciones productoras de semilla, con el fin de garantizar una producción de calidad.

Aplicación del reglamento de la ley de semillas vigente, Acuerdo Ministerial 494 del 26 de octubre del 2012. Aquí señalaremos varios indicadores utilizados:

\section{Cultivo frejol (Phaseolus vulgaris)}

Podrá aceptarse para certificación el campo de multiplicación que en el ciclo anterior de producción se haya sembrado con frejol o soya de la misma variedad.

Tabla 2. Factores de campo

\begin{tabular}{lccc}
\hline \multicolumn{1}{c}{ FACTORES } & BÁSICA & REGISTRADA & CERTIFICADA \\
\hline $\begin{array}{l}\text { Aislamiento metros } \\
\quad \text { Malezas nocivas al momento de la }\end{array}$ & 10 & 10 & 10 \\
fiscalización, el campo no debe contener & & & \\
en total más de 50 plantas por hectárea & & & \\
Malezas altamente nocivas & 0 & 0 & 0 \\
Otras variedades (pl/ha) & 0 & 6 & 8 \\
Otros cultivos & 0 & 4 & 8 \\
\hline
\end{tabular}

El campo que vaya a dedicarse a la multiplicación de semilla de papa, no puede haber sido sembrado con papa durante los dos años anteriores de producción. Podrá aceptarse campos sembrados con la misma variedad y aprobados para certificación.

Enfermedades: se aceptara una incidencia de enfermedades o plagas, de acuerdo con las siguientes tolerancias expresadas en porcentajes:

Tabla 3. Factores de cultivo de frejol

\begin{tabular}{lcccccc}
\multicolumn{1}{c}{ FACTORES } & \multicolumn{2}{c}{ BÁSICA } & \multicolumn{2}{c}{ REGISTRADA } & \multicolumn{2}{c}{ CERTIFICADA } \\
& \multicolumn{2}{c}{ INSPECCIÓN } & \multicolumn{2}{c}{ INSPECCIÓN } & \multicolumn{2}{c}{ INSPCCIÓN } \\
\cline { 2 - 7 } & $1 \mathrm{a}$ & $2 \mathrm{a}$ & $1 \mathrm{a}$ & $2 \mathrm{a}$ & $1 \mathrm{a}$ & $2 \mathrm{a}$ \\
\hline Mosaico suave y severo & 8 & 2 & 10 & 4 & 12 & 5 \\
Mosaico rugoso & 1 & 0 & 1.5 & 0.5 & 2 & 1 \\
Enrollamiento de hojas & 2 & 1 & 4 & 2 & 5 & 2 \\
Amarillamiento de venas & 8 & 2 & 10 & 4 & 12 & 5 \\
Otros virus & 3 & 1 & 5 & 2 & 8 & 3 \\
Total virus Aceptable & 8 & 2 & 12 & 4 & 12 & 8 \\
Marchitez bacteriana (Pseudomonas & 0 & 0 & 0 & 0 & 0 & 0 \\
solancearum) & 1 & 0 & 2 & 1 & 4 & 2 \\
Pata negra (Erwiniasp.) & 8 & 4 & 12 & 6 & 14 & 7 \\
Rhizoctonia (Rhizoctonia solani) & 0.02 & 0 & 0,02 & 0 & 0.05 & 0.02 \\
Lanosa (no identificada) & 0 & 0 & 0 & 0 & 0 & 0 \\
Nematodos patógenos & & & & & & \\
\hline
\end{tabular}




\section{Maíz (Zea mays)}

Cosecha anterior.- El campo que vaya a dedicarse a la multiplicación de semilla de maíz, no puede haber sido sembrado con maíz, en la cosecha anterior. Cuando se trate de variedades comerciales. Podrá aceptarse para certificación el campo de multiplicación que en el ciclo anterior de producción se haya sembrado con maíz de la misma variedad.

Tabla 4. Factores de laboratorio

\begin{tabular}{lcc}
\hline FACTORES & BÁSICA & CERTIFICADA \\
\hline Germinación (\% mínimo) & 90 & 90 \\
Semilla pura (\% mínimo) & 98 & 97 \\
Materia inerte (\% máximo) & 2 & 2 \\
Malezas comunes (sem./kg./max) & 0 & 2 \\
Malezas nocivas (sem./kg./max) & 0 & 1 \\
Malezas altamente nocivas (sem./kg./max) & 0 & 0 \\
Otros cultivos (sem./kg./max) & 0 & 2 \\
Humedad (\% máximo) & 14 & 14 \\
Semillas fuera de tipo (sem./kg./max) & 1 & 5 \\
\hline
\end{tabular}

Artículo 25. Cualquier cantidad de semilla que se expenda, llevará adherido al empaque el marbete indicativo de la clase y categoría de semilla correspondiente, en la siguiente forma:

- Marbete blanco: categoría básica

- Marbete rojo: categoría registrada

- Marbete celeste: categoría celeste; y,

- Marbete amarillo: categoría común. 


\section{RESULTADOS Y DISCUSIÓN}

A continuación presentamos varios indicadores sobre producción de semillas:

Tabla 5. Ejecución y seguimiento de lotes de semilla.

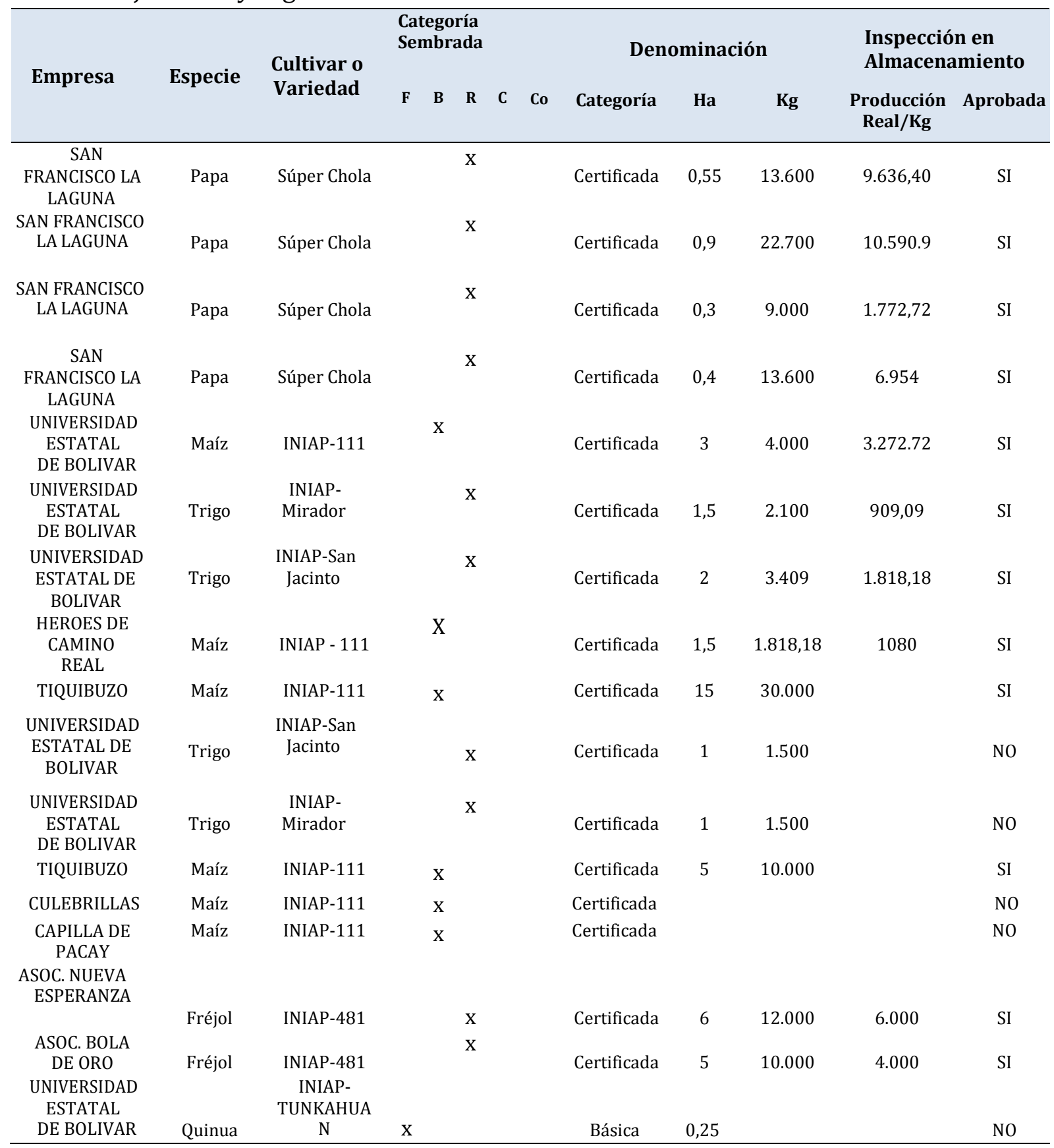

Desde la modificación del reglamento de la ley de semillas (2012), con el apoyo de la FAO, desde el 2011 se fomenta el acceso y uso de semilla de calidad. Esta modificación permitió realizar un cambio en los procesos de producción de semillas en la provincia Bolívar de los tradicionales y no convencionales (Proceso Artesanal de Semillas PAS*) al SISTEMA FORMAL de producción de semillas. 
En la tabla 5 se registró la participación de ocho organizaciones legales de pequeños agricultores como semilleritos ante el MAGAP en la Dirección Agropecuaria de Bolívar que se dedicaron a la multiplicación y distribución de semilla de calidad. Varios cultivos formaron parte de la producción de semillas como; maíz, trigo, quinua, papa, en una superficie de 43,15 hectáreas las mismas que cumplieron con las normativas de rotación de cultivos, aislamiento, análisis de nematodos (dependiendo del cultivar), entre otros.

Tabla 6. Producción de semilla de papa categoría certificada.

\begin{tabular}{clccccc}
\hline & & & & & $\begin{array}{c}\text { (X) } \\
\text { PROMEDIO }\end{array}$ & $\begin{array}{c}\text { PORCENTAJE DE } \\
\text { EXTRACIÓN }\end{array}$ \\
CULTIVO & ESÉCIE & Ha & Kg & Real/Kg & $\begin{array}{c}\text { Extracción } \\
\text { de semilla }\end{array}$ & $\begin{array}{c}\text { De semilla } \\
\text { recomendado }\end{array}$ \\
\hline PAPA & SUPERCHOLA & 2,15 & 58900 & 28954,02 & 47,09 & \\
MAIZ & INIAP-111 & 24,5 & 45818,18 & 4352,72 & 70,61 & \\
& INIAP & & & & $60 \%-70 \%$ & \\
TRIGO & MIRADOR, I- & 5,5 & 8509 & 2727,27 & 48,1 & \\
& SAN JACINTO & & & & & \\
FREJOL & INIAP-481 & 11 & 22000 & 10000 & & \\
PROMEDIO DE EXTRACCIÓN & & & & & \\
DE SEMILLA & & & & & & \\
\hline
\end{tabular}

Si comparamos la tasa extracción de semillas es menor a la recomendada debido principalmente al manejo inadecuado en post-cosecha, en el caso del cultivo de papa a pesar de la aplicación de la normativa la demora de la cosecha provoca que el tubérculo permanezca mucho más tiempo en contacto con los microorganismos patógenos del suelo deteriorando la calidad de la semilla. Una semilla de calidad debe reunir los siguientes atributos: Pureza genética, física, fisiológica y sanitaria. (Tabla 6).

Terenti (2004), señala que en el contexto de las semillas la calidad puede subdividirse en cuatro cualidades básicas: genética, fisiológica, sanitaria y física. La presencia de las cuatro cualidades esenciales en su máximo nivel permite que la semilla esté en su máxima calidad integral. Cada una de ellas aporta su capacidad para originar plantas productivas. La debilidad en cualquiera de ellas introduce un factor limitante y como consecuencia plantas poco productivas.

Para la producción de semillas la rotación de cultivos es una actividad muy recomendada por sus ventajas que brinda, al respecto Brechelt, (2004). Menciona que la rotación de cultivos es la única medida rentable de control de determinados nemátodos $\mathrm{u}$ organismos patógenos, por ejemplo hongos que viven en el suelo. El principio de este método consiste en retardar la siembra siguiente de la planta huésped hasta que las condiciones de vida para los organismos no les permitan sobrevivir. Una rotación adecuada de cultivos es especialmente eficaz para privar de nutrientes a organismos que debido a su escasa movilidad o de estenofagia, dependen de una única planta hospedera, demostrando menor eficacia contra organismos polífagos o móviles. 


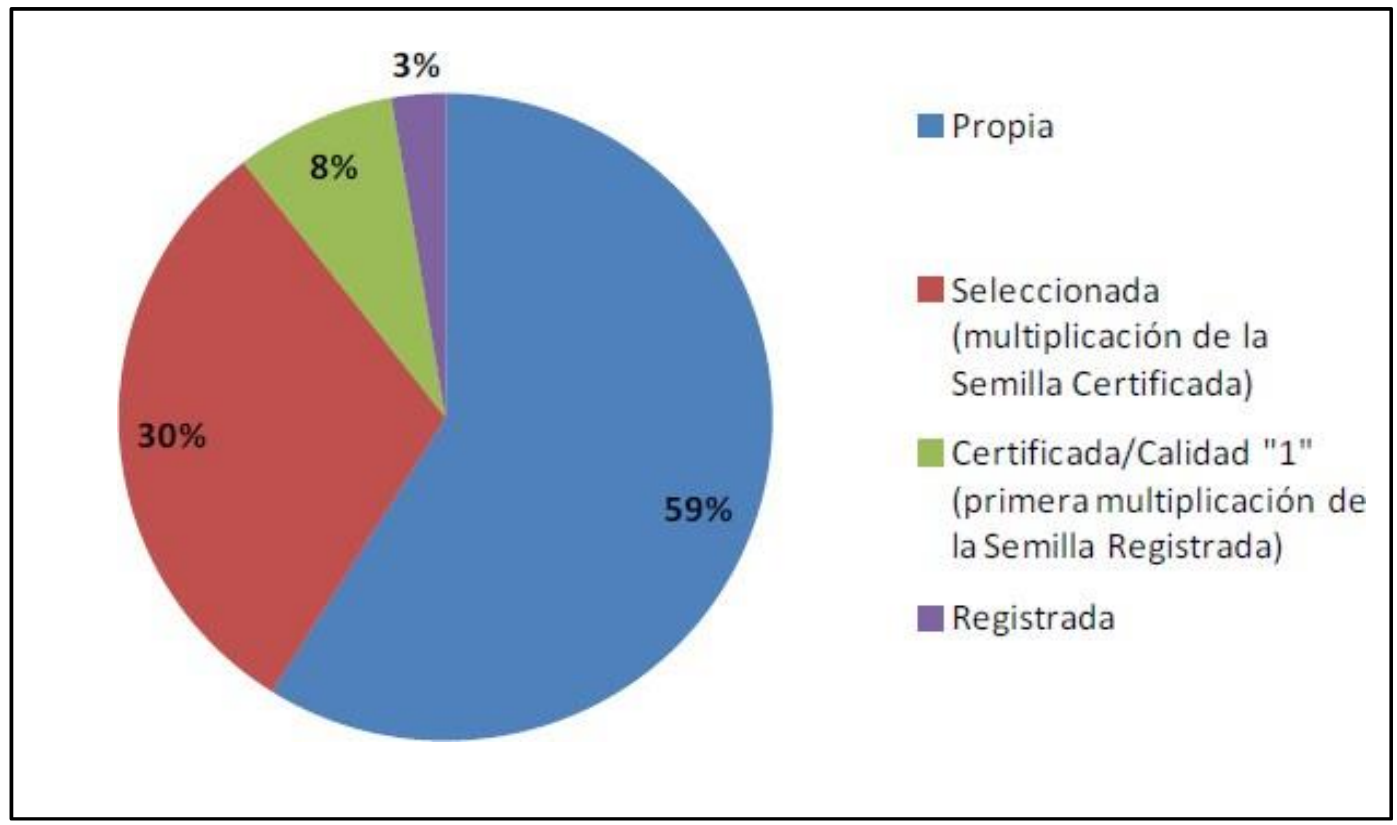

Gráfico 1. Tipo de Semilla demandada por los productores de papa en Ecuador Fuente: Flores et al., 2012.

El uso de semilla certificada en el caso de papa, representó a nivel nacional sólo el 3\% de la superficie sembrada mientras que en la provincia de Bolívar apenas el 0,14\%. Si consideramos que en provincia de Bolívar se siembra alrededor de 3500 hectáreas, la producción de 28954,02 $\mathrm{kg}$. de semilla certificada de papa en el 2013 fue insuficiente existiendo una demanda potencial. En el año 2013 se registró una superficie de 43 hectáreas de producción de semilla en diferentes cultivos ya en el año 2014 se elevó a 113 hectáreas.

\section{CONCLUSIONES}

La rotación de cultivos brinda muchos beneficios en lotes de producción de semillas tales como: romper el ciclo biológico de plagas, enfermedades y malezas además incorpora materia orgánica y nutriente al suelo, entre otros.

La producción de semillas desde el punto de vista empresarial de las organizaciones está encaminado hacia el cambio de la matriz productiva; cuya sostenibilidad depende de varios factores entre los cuales se puede mencionar: planificación, organización, valores corporativos, entre otros.

La modificación en las normativas de producción de semilla en Ecuador permite que se cumplan con los parámetros exigidos por la ley para garantizar la semilla de calidad.

En la provincia de Bolívar existe una demanda insatisfecha sobre el acceso a semillas de calidad que debe ser cubierta.

\section{REFERENCIAS}

Brechelt, A. (2004). El Manejo Ecológico de Plagas y Enfermedades. Red de Acción en Plaguicidas y sus Alternativas para América Latina. Consultado el 03/10/2014. Disponible en: http://www.rapal.org/articulos_files/Ma nejo_Ecologico_de_Plagas_A.Bretchel.pdf

Flores, R., Naranjo, H., Galárraga, J., Sánchez M.P., Y Viteri, S. (2012). Estudio de la 
demanda de semilla de papa de calidad en Ecuador. Documento de trabajoEcuador. $\mathrm{N}^{\circ} 1$. Proyecto "Fortalecimiento de la innovación agrícola pro pobre para seguridad alimentaria en la región andina- Iss Andes". OFIAGRO, Centro Internacional de la Papa. Consultado el 26/09/14. Disponible en: http://cipotato.org/wpcontent/uploads/2014/07/005838.pdf

Mora, E., Pumisacho, M., y Reinoso, I. (2011). Investigación y validación de componentes de Manejo integrado de patógenos de suelo en el cultivo de papa, con pequeños agricultores de la Sierra Centro. Consultado el 25/09/2014. Disponible en: http://www.quito.cipotato.org/4_Nac_pa pa/Memorias/e_mora_memoria.pdf

Pulgar, I. (2012). Estudio de mercado de semillas certificadas: Papa, Maíz Amiláceo, Fréjol. Consultor FAO. Consultado el 26/09/14. Disponible en: http:// www.rlc.fao.org/fileadmin/templates/esfao/content/documentos/Proyectos/Public aciones/2do_estudio_de_mercado_2012.12. 13.pdf
Saltos, R., Saltos, J. (2011). Cuantificación de la Diversidad Biológica (macrofauna) edáfica en 4 ecosistemas en la comunidad Potrerillos, provincia Bolívar, Ecuador. In Simposio Internacional de Recursos Genéticos para América Latina y el Caribe, Quito- Ecuador

Terenti, O. (2004). Calidad De Semilla, ¿Qué Implica y Cómo Evaluarla? E.E.A. INTA San Luis, Informativo Rural 1(2). Consultado el 26/09/14. Disponible en: http://www.produccionanimal.com.ar/produccion_y_manejo_past uras/pasturas $\% \quad 20$ artificiales/27calidad_semillas.pdf

Torres, H. (2014). Producción de Tubérculossemillas de Papa. Manual de Capacitación. Fascículo 3.3. Centro Internacional de la Papa. Consultado el 25/09/2014. Disponible en: http://www.neiker.net/neiker/papata/d ocumentos/manuales/manuales\%20CIP/ Principales\%20Enfermedades\%20fungic as\%20de\%20la\%20papa.pdf 